ISSN 2236-0859

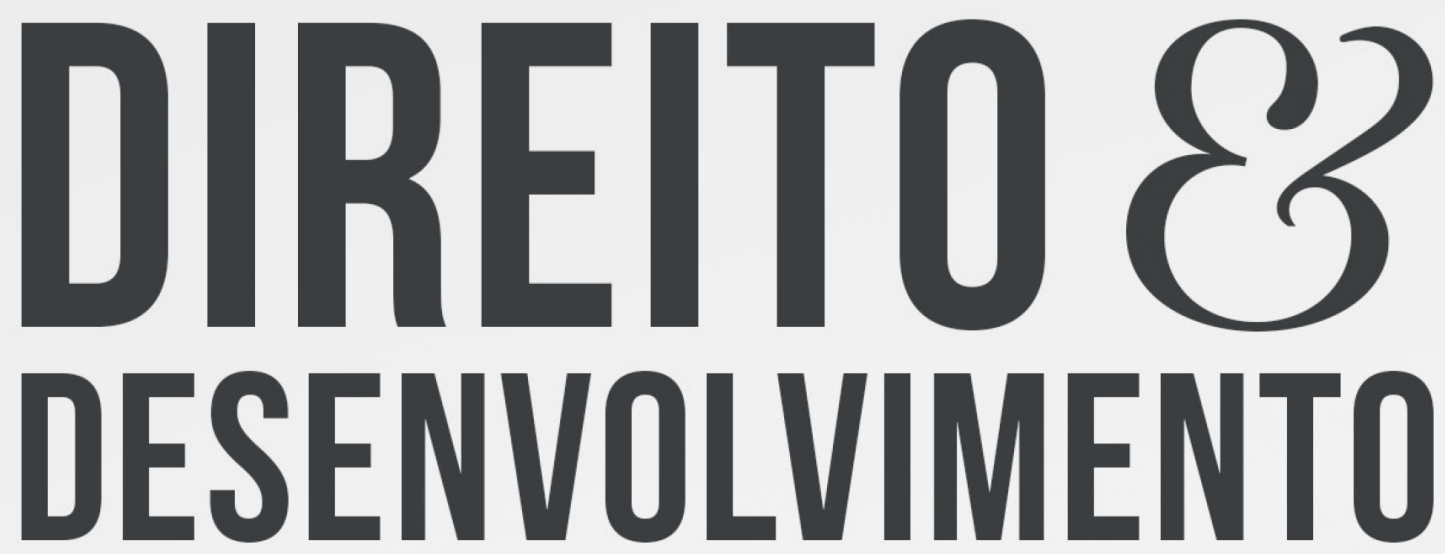

REVISTA DO PROGRAMA DE PÓS-GRADUAÇ̃̃O EM DIREITO MESTRADO EM DIREITO E DESENVOLVIMENTO SUSTENTÁVEL

DIREITODE COMUNIDADES TRADICIONAIS FACE AO AGRONEGÓCIO: ANÁLISE DA TUTELA DE DIREITOS DESDE RESISTÊNCIAS À MONOCULTURA DA SOJA NO BAIXO PARNAÍBA MARANHENSE

RUAN DIDIER BRUZACA 


\title{
DIREITO DE COMUNIDADES TRADICIONAIS FACE AO AGRONEGÓCIO: ANÁLISE DA TUTELA DE DIREITOS DESDE RESISTÊNCIAS À MONOCULTURA DA SOJA NO BAIXO PARNAÍBA MARANHENSE
}

\section{TRADITIONAL COMMUNITIES RIGHTS FACING AGRIBUSINESS: ANALYSIS OF THE PROTECTION OF RIGHTS FROM RESISTANCE TO THE SOY MONOCULTURE IN BAIXO PARNAÍBA MARANHENSE}

Recebido: 01/08/2020

Ruan Didier Bruzaca'

Aprovado: 01/12/2020

\section{RESUMO:}

A realidade brasileira é marcada por conflitos decorrentes do modelo de desenvolvimento adotado no país, como os envolvendo o agronegócio, caracterizado por monocultivos, latifúndios e contrastes ambientais e territoriais. Com isso, este trabalho científico tem como tema o impacto do agronegócio sobre os direitos de comunidades tradicionais. De forma delimitada, analisa o contexto do Baixo Parnaíba maranhense com foco na efetividade de direitos daqueles grupos étnicos nos conflitos socioambientais provocados pelo monocultivo da soja. $\mathrm{O}$ problema remete à indagação de em que medida as resistências das comunidades tradicionais atingidas pelo agronegócio contribui para a efetividade de direitos. Acolhe-se a hipótese de que as comunidades se contrapõem ao modelo de produção adotado pelos empreendedores do agronegócio, caracterizado por ser ambiental, social e culturalmente prejudicial, repercutindo em outras formas de construir o direito. O objetivo geral é analisar a relação entre o agronegócio e a consagração de direitos de comunidades tradicionais. Especificamente, busca destacar o avanço territorial do agronegócio no Brasil e no Maranhão, apresentar a relação entre o avanço territorial do agronegócio e os impactos sobre o ambiente e os direitos e examinar as implicações da resistência das comunidades tradicionais ao avanço do agronegócio no Baixo Parnaíba maranhense. Realizou-se pesquisa bibliográfica e documental, com levantamento de dados do Instituto Brasileiro de Geografia e Estatística do ano de 2008 a 2016 e do Instituto Brasileiro do Meio Ambiente e dos Recursos Naturais Renováveis a respeito da comercialização de agrotóxicos de 2009 a 2016.

Palavras-chave: Agronegócio. Baixo Parnaíba maranhense. Comunidades tradicionais. Soja.

\begin{abstract}
:
The Brazilian reality is marked by conflicts resulting from the development model adopted in the country, such as those involving agribusiness, characterized by monocultures, large estates and environmental and territorial contrasts. Thus, the scientific work theme ins the impact of agribusiness on the rights of traditional communities. The delimited theme is the analyzes of

1 Doutor em Ciências Jurídicas pela Universidade Federal da Paraíba (UFPB), com período sanduíche na Universitá Degli Studi di Firenze (UNIFI); Mestre em Direito e Instituições do Sistema de Justiça pela Universidade Federal do Maranhão (UFMA). Professor Assistente A, Nível 2, da UFMA e professor da Unidade de Ensino Superior Dom Bosco (UNDB) email: ruandidier@gmail.com
\end{abstract}


Baixo Parnaíba maranhense context with a focus on the effectiveness of the rights of those ethnic groups in the socio-environmental conflicts caused by the monoculture of soy. The problem leads to the question of the extent to which the resistance of traditional communities affected by agribusiness contributes to the effectiveness of rights. The hypothesis is that communities are opposed to the production model adopted by agribusiness entrepreneurs, characterized by being environmentally, socially and culturally harmful, resulting in other ways of building law. The general objective is to analyze the relationship between agribusiness and the effectivity of rights of traditional communities. Specifically, it seeks to highlight the territorial advance of agribusiness in Brazil and Maranhão, present the relationship between the territorial advance of agribusiness and the impacts on the environment and rights, examining the implications of the resistance of traditional communities to the advance of agribusiness in Baixo Parnaíba maranhense. Bibliographic and documentary research was carried out, with data collection from the Brazilian Institute of Geography and Statistics from 2008 to 2016 and from the Brazilian Institute of the Environment and Renewable Natural Resources regarding the marketing of pesticides from 2009 to 2016.

Key-words: Agribusiness. Baixo Parnaíba maranhense. Traditional communities. Soy.

\title{
1 INTRODUÇÃO
}

\author{
Ó donos do agrobiz, ó reis do agronegócio \\ Ó produtores de alimento com veneno \\ Vocês que aumentam todo ano sua posse \\ E que poluem cada palmo de terreno \\ E que possuem cada qual um latifúndio \\ E que destratam e destroem o ambiente \\ De cada mente de vocês olhei no fundo \\ E vi o quanto cada um, no fundo, mente \\ (“Reis do agronegócio", de Carlos Rennó e Chico César)
}

O agronegócio reflete na realidade brasileira as implicações de modelos de desenvolvimento que consolidam o país enquanto produtor de bens primários para exportação, como é o caso da soja, grão que assume grande importância no mercado de exportações. Neste cenário, o avanço das monoculturas no país repercute em variados impactos, como os relacionados ao ambiente, ao território e aos direitos.

O tema do presente artigo científico é o impacto do agronegócio sobre os direitos de comunidades tradicionais. De forma delimitada, analisando-se em consideração o contexto do Baixo Parnaíba maranhense, dar-se-á enfoque à efetividade de direitos pelas resistências destes grupos no cenário de conflitos socioambientais provocados pelo monocultivo da soja.

A problemática do presente estudo refere-se à indagação de em que medida as resistências das comunidades tradicionais atingidas pelo agronegócio, tal qual se observa nos conflitos envolvendo a soja no Baixo Paranaíba maranhense, contribui para a efetividade de direitos. Tem-se como premissa principal que os direitos são efetivados na medida em que as comunidades tradicionais se contrapõem ao modelo de produção adotado pelos empreendedores, caracterizado por ser ambiental, social e culturalmente prejudicial.

Para tal, tem-se como objetivo geral analisar relação entre o agronegócio e a consagração de direitos de comunidades tradicionais. Especificamente, busca-se: 1) destacar o avanço territorial do agronegócio no Brasil e no Maranhão; 2) apresentar a relação entre o 
avanço territorial do agronegócio e os impactos sobre o ambiente e os direitos; 3) examinar as implicações da resistência das comunidades tradicionais ao avanço do agronegócio no Baixo Parnaíba maranhense.

Metodologicamente, além da realização de pesquisa bibliográfica e documental, destaca-se o levantamento de dados do Instituto Brasileiro de Geografia e Estatística a respeito do espaço ocupado pelo agronegócio, em particular pela soja, no Brasil, no Maranhão e no Baixo Parnaíba maranhense, do ano de 2008 a 2016. Intentando destacar as implicações ambientais do agronegócio, também se realizou levantamento de dados do Instituto Brasileiro do Meio Ambiente e dos Recursos Naturais Renováveis a respeito da comercialização de agrotóxicos de 2009 a 2016, no Brasil e no Maranhão.

\section{O DESENHO DO AMBIENTE PELO CENÁRIO NEODESENVOLVIMENTISTA: AVANÇOS DO AGRONEGÓCIO SOBRE O TERRITÓRIO BRASILEIRO E MARANHENSE}

Os debates sobre neodesenvolvimentismo, ou novo desenvolvimentismo, tem ganhado atenção desde o seu surgimento enquanto balizador da política de desenvolvimento do Brasil. Neste aspecto, o país insere-se num contexto que mantém o aprofundamento do capital internacional e nacional em diferentes espaços do país, o que gera conflitos com grupos marcados por formas diferenciadas de criar, de ser e de viver, a exemplo do que ocorre no Maranhão com as comunidades tradicionais.

Do início da ditadura civil-militar, em 1964, até o seu fim, no ano de 1985, tem-se o chamado segundo ciclo do desenvolvimentismo (BIELSCHOWSKY, 2009, passim), no qual se observa em seus governos (Castelo Branco e Costa e Silva, Médici, Geisel e Figueiredo) formas diferentes e não-lineares de articulação na consolidação das políticas de desenvolvimento, mas com características comuns. É o caso da abertura para o capital internacional, do aprofundamento do capital no território brasileiro (em especial, na Amazônia, o que afeta o Maranhão), da inserção do país na divisão internacional do trabalho enquanto provedor de produtos primários, dos investimentos em infraestruturas e do desrespeito a direitos da população étnica excluída, principalmente no campo (BRUZACA, 2014, passim).

Trata-se de um modelo que marcou a economia brasileira, cujas políticas de desenvolvimento das últimas décadas guardam ainda relação. Neste sentido, Augusto et. al. (2015, p. 98) destaca que no segundo governo de Fernando Henrique Cardoso ocorreu a rearticulação do "processo de modernização técnica da agropecuária, que se fizera pelos militares nos anos 1960 e 1970", caracterizando o país como provedor de bens primários no cenário internacional. Ademais, houve a reestruturação de "aliança das cadeias agroindustriais, da grande propriedade fundiária e do Estado, promovendo um estilo de expansão agrícola, sem reforma social". Finaliza-se destacando que os governos Lula (2003-2010) e Dilma (20112015) intensificaram tal modelo.

É justamente este último período que se nomeia "neodesenvolvimentismo" ou "novo desenvolvimentismo". Segundo Santos (2013, p. 92-93), refere-se a um modelo de acumulação mais nacionalista e estatista, baseado no neoextrativismo, com centralização no Estado, intervindo no mercado nacional e internacional. Sobre a questão do extrativismo, Gudynas (2016, p. 26-27, traduziu-se) destaca a existência de extrativismos conservadores reajustados (Colômbia, Chile, Paraguai e Peru) e progressistas (Argentina, Bolívia, Equador, Uruguai e Venezuela), tendo diferenças na "estruturação econômica, [no] papel do Estado, [no] uso de excedentes e [na] legitimação de políticas”, estando o Brasil no segundo grupo. 
Buscou-se solucionar o déficit advindo do governo de Fernando Henrique Cardoso, acelerando-se as exportações primárias e alcançando "superávits nas transações externas durante o período de 2003 a 2007, criando certa euforia passageira", mas que aumenta em 2008. A gravidade está "na dependência de capital estrangeiro, por um lado, e na ampliação dos custos sociais desse estilo de crescimento, por outro. Os custos sociais da especialização econômica do setor primário ainda não estão suficientemente percebidos pela sociedade" (AUGUSTO, et. al., 2015, p. 98).

O momento de recrudescimento de 2008 referencia o início do segundo mandato de Luís Inácio Lula da Silva, que utiliza um discurso sobre a necessidade de uma política econômica que retome o "crescimento econômico", dando destaque ao "desenvolvimento industrial e agrícola" (MOTA, 2010, s. p.). Neste momento, observa-se o aumento de atividades como as relacionadas ao agronegócio, o que implicará, conforme se verá adiante, na agudização de conflitos socioambientais, impactando comunidades tradicionais.

Sobre a ideia da palavra "agronegócio", destaca-se:

[...] tem origem na década de 1990 e representa uma construção ideológica na tentativa de consolidar uma imagem de novo modelo de desenvolvimento da agricultura: sofisticado, eficiente, produtivo, em contraposição à imagem da agricultura capitalista vinculada ao latifúndio, que carrega o estigma da exploração, do trabalho escravo, da extrema concentração da terra, do coronelismo, do clientelismo, da improdutividade e do desmatamento. Na verdade, representam o mesmo modelo que domina historicamente a produção agrícola no país - grandes propriedades de terras que produzem para exportação -, mas que sofre modificações e adaptações em suas diferentes fases, intensificando a exploração da terra e do homem (AUGUSTO, et. al., 2015, p. 172).

Trata-se de um esquema de produção associado a concepções desenvolvimentistas que se aprofunda no Brasil. Como exemplo, tem-se a monocultura da soja ${ }^{2}$, que assume a posição de um dos principais produtos de exportação do país. Isto também pode ser observado em regiões e estados específicos, como é o caso do Maranhão. Ocorre que o agronegócio, na esteira daquele modelo de desenvolvimento, impõe uma lógica de produção e apropriação da natureza distante das formas de cultura e criação realizadas pelas comunidades tradicionais.

No agronegócio, diferente da agricultura, "não há cultura, pois não há povo, [na qual] a relação homem-natureza é mediada pelos valores do mercado, do negócio" (AUGUSTO, et. al., 2015, p. 123, acréscimos nossos). Neste contexto da expansão da agricultura industrial ou agronegócio, observa-se a concentração de terras para a monocultura de alimentos ou de agrocombustível. Acarreta na reprimarização da economia, expansão da fronteira agrícola, modernização agrícola e monocultura químico-dependente. Ademais, os cultivos ocupam vastas terras não para alimentar as populações, mas para sustentar ciclos produtivos, ocasionando graves impactos socioambientais (SANTOS, 2013, p. 96).

Especificamente, o agronegócio repercute no "desenhar" do ambiente, afirmação que se extrai do conceito de "efeito derrame" de Gudynas (2016, p. 28). Tal conceito possibilita compreender as condições e transformações provocadas por empreendimentos econômicos no espaço geográfico, resultando em modificações no direito, na gestão ambiental, no território, por exemplo, para acolher a atividade. Continuando, o referido autor destaca existir também mudanças nas políticas públicas, na justiça e na economia, estando tais efeitos entrelaçados.

2 Sobre esta afirmativa, destaca-se: "Entre 1990 e 2007, a área plantada com soja no Brasil cresceu cerca de $114 \%$, passando de 9,74 para 20,87 milhões de hectares. Nesse período, merece destaque o aumento da área plantada com soja na região CentroOeste (+6,4 milhões de hectares) e na região Nordeste (+1,2 milhão de hectares), representando a consolidação dessas regiões como aquelas da fronteira agrícola da soja” (SCHLESINGER, NUNES, 2008, p. 25). Ademais, importa destacar, como será apresentado mais adiante, conforme dados do Instituto Brasileiro de Geografia e Estatística, que desde 2008 a soja é o produto que mais ocupa espaço no território brasileiro, em comparação a outros plantios (IBGE, 2008; 2009; 2010; 2011; 2012; 2013; 2014; 2015; 2016). 
Um destes seria o "derrame territorial", no qual o extrativismo impõe novos tipos de territorialidade, que se sobrepõem a outros existentes, como indígenas, campesinas, áreas protegidas etc. Com isto, ou debilitam ou anulam estas, a exemplo da proteção de territórios indígenas, que pode ser relativizadas a qualquer momento. Este redesenho territorial pode cobrir parte considerável dos países (GUDYNAS, 2016, p. 30-31).

Levando em consideração o espaço territorial ocupado pela soja que, como destacado, é considerado um produto de grande relevância para a economia, apresentam-se dados sobre as áreas plantadas para sua produção, possibilitando perceber a dimensão que o agronegócio vem assumindo. Para tal, foram levantados do ano de 2007 a 2016 dados do Instituto Brasileiro de Geografia e Estatística, referentes ao Plano Agrícola Municipal - Culturas Temporárias e Permanentes, analisando-se a tabela 15 ("Área plantada ou área destinada à colheita, área colhida, quantidade produzida, rendimento médio e valor da produção dos principais produtos das lavouras temporárias e permanentes em ordem decrescente de área colhida").

No Brasil, observa-se o crescimento da área destinada à soja, cujos dados ${ }^{3}$ podem ser organizados conforme o gráfico abaixo:

Gráfico 1 - Área plantada ou área destinada à colheita, área colhida, quantidade produzida, rendimento médio e valor da produção dos principais produtos das lavouras temporárias e permanentes em ordem decrescente de área colhida no Brasil.

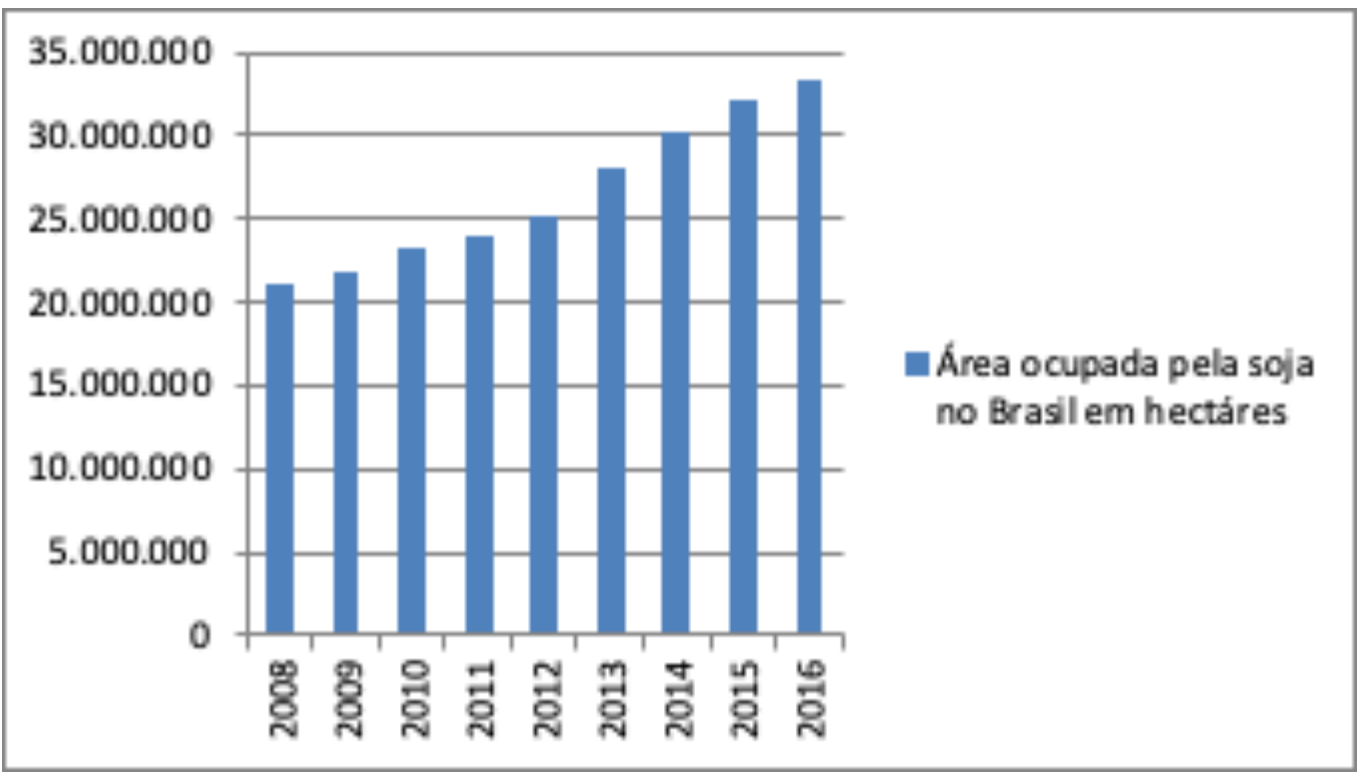

Fonte: IBGE (2008, 2009, 2010, 2011, 2012, 2013, 2014, 2015, 2016).

Elaboração do gráfico: autor.

O mesmo se observa com dados referentes ao Maranhão ${ }^{4}$, apesar de um decrescimento do primeiro para o segundo ano, conforme gráfico que segue:

\footnotetext{
3 Quanto aos números, destaca-se: em 2008, 21.063 .721 ha; em 2009, 21.761.782 ha; em 2010, 23.339.094 ha; em 2011, 24.032.410 ha; em 2012, 25.090.559 ha; em 2013, 27.948.605 ha; em 2014, 30.308.231 ha; em 2015, 32.206.387 ha; em 2016, 33.309.865 ha (IBGE, 2008; 2009; 2010; 2011; 2012; 2013; 2014; 2015; 2016).

4 Quanto aos dados, destaca-se: em 2008, 421.520 ha, sendo o segundo maior produto a ocupar espaço no Estado, perdendo para o arroz, que era de 467.405 ha; em 2009, 409.402 ha, novamente com o arroz ocupando área maior, de 472.621 ha; a partir de 2010 passa a ser o produto com maior área ocupada, com 495.756 ha; em 2011, 530.539 ha; em 2012, 556.178 ha; em 2013, 564.546 ha; em 2014, 677.540 ha; em 2015, 761.225 ha; em 2016, 783.654 ha (IBGE, 2008; 2009; 2010; 2011; 2012; 2013; 2014; 2015; 2016).
} 
Gráfico 2 - Área plantada ou área destinada à colheita, área colhida, quantidade produzida, rendimento médio e valor da produção dos principais produtos das lavouras temporárias e permanentes em ordem decrescente de área colhida no Maranhão.

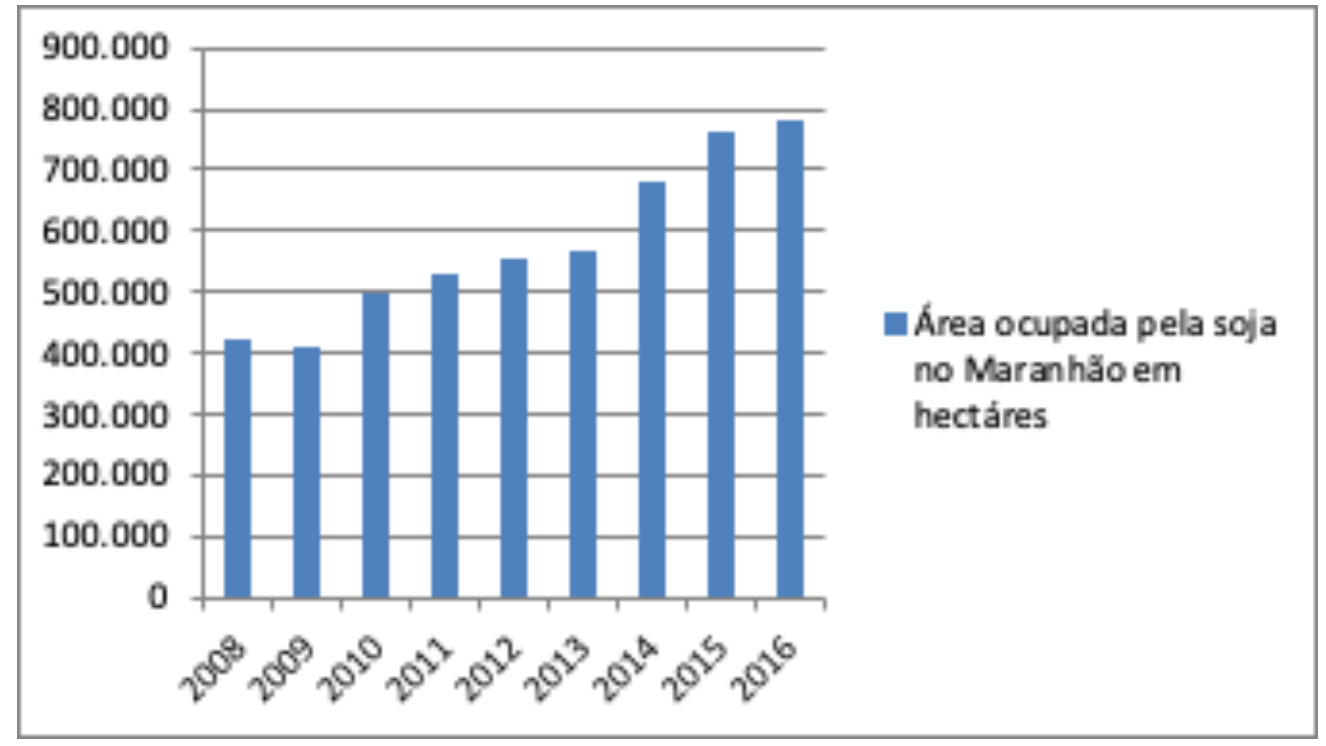

Fonte: IBGE (2008, 2009, 2010, 2011, 2012, 2013, 2014, 2015, 2016).

Elaboração do gráfico: autor.

Iniciada a seleção de dados do Instituto Brasileiro de Geografia e Estatística desde 2008, verifica-se que a soja é o produto que mais ocupa espaço no Brasil até o ano de 2016 e, no Maranhão, desde 2010 até 2016 (IBGE, 2008; 2009; 2010; 2011; 2012; 2013; 2014; 2015; 2016). A produção do referido bem primário, voltado para a exportação, referencia o momento da política do desenvolvimento do país, o que implica também na configuração da economia do estado-membro objeto de análise do presente artigo.

Não obstante, este desenho do ambiente conforme um dado modelo de produção não se distancia das constatações de Escobar (2003, p. 157) a respeito da desconsideração dos atropelos decorrentes da noção dominante de desenvolvimento, que levam, por exemplo, aos deslocamentos forçados de grupos étnicos. Repercute ademais em fragmentações das relações familiares, de inseguranças em relação ao território. Continuando, atenta o autor colombiano que modernidade e desenvolvimento são "projetos culturais-espaciais", requerendo a conquista de territórios e de pessoas, bem como de sua transformação ecológica e cultural, de acordo com suas bases racionais e logocêntricas.

Deste modo, verifica-se como um esquema de desenvolvimento, que se denominou de novo desenvolvimentismo ou neodesenvolvimentismo, repercutiu no incentivo de uma específica atividades agrícola, ou seja, o agronegócio. Neste, tem-se como exemplo a soja, que ano após ano ocupa mais territórios tanto no Brasil quanto no Maranhão. De início, percebe-se que essa apropriação territorial resulta na reconfiguração do ambiente. Entretanto, necessário se faz especificar outras implicações socioambientais que se envolvem com o nomeado derrame territorial. 


\section{TRAÇOS DOS CONFLITOS SOCIOAMBIENTAIS PROVOCADOS PELO AGRONEGÓCIO: DO ENTRELACE ENTRE OS DERRAMES}

Conforme destacado, o modelo de desenvolvimento adotado no Brasil resulta em uma apropriação territorial. Entretanto, trata-se de apenas um dos aspectos provocados pelo esquema baseado no extrativismo, cujo conceito foi anteriormente abordado. Por isto, relevante se faz pontuar algumas implicações que se relacionam com o nomeado derrame territorial.

Retomando a tipologia utilizada por Gudynas, destacar-se-á três tipos de derrame: derrames ambientais; derrames de direitos e extrações e; derrame de compensações e justiça. Quanto aos derrames ambientais, consistem: 1) no reforço da mercantilização da Natureza, convertendo-a em mercadoria, fragmentando a natureza em serviços com e sem valor econômico - sendo estes últimos invisibilizados ou irrelevantes; 2) na redução das exigências, controles ou sanções ambientais, que constituem "flexibilizações" - a exemplo das pressões ao governo Lula, no Brasil voltado para flexibilizações que afetam todo o marco normativo e regulatório ambiental (GUDYNAS, 2016, p. 28-30). Neste primeiro derrame, pode-se destacar o aprofundamento do uso de agrotóxicos, considerados, como se apresentará, maléficos ao ambiente e à saúde humana, bem como inconciliável às práticas tradicionais.

No contexto brasileiro, é latente o uso de agrotóxicos, que cresce ao passo que o agronegócio ocupa espaço territorial. Com isso, destaca-se gráfico que possibilita verificar a sua comercialização no país, com base na "Venda de agrotóxicos e afins no Brasil no período de 2009 a 2016 ", utilizando como unidade a tonelada de ingrediente ativo. Com isso, obtémse o seguinte gráfico:

Gráfico 3 - Vendas de agrotóxicos e afins no Brasil no período de 2000 a 2016 (unidade: tonelada de ingrediente ativo)

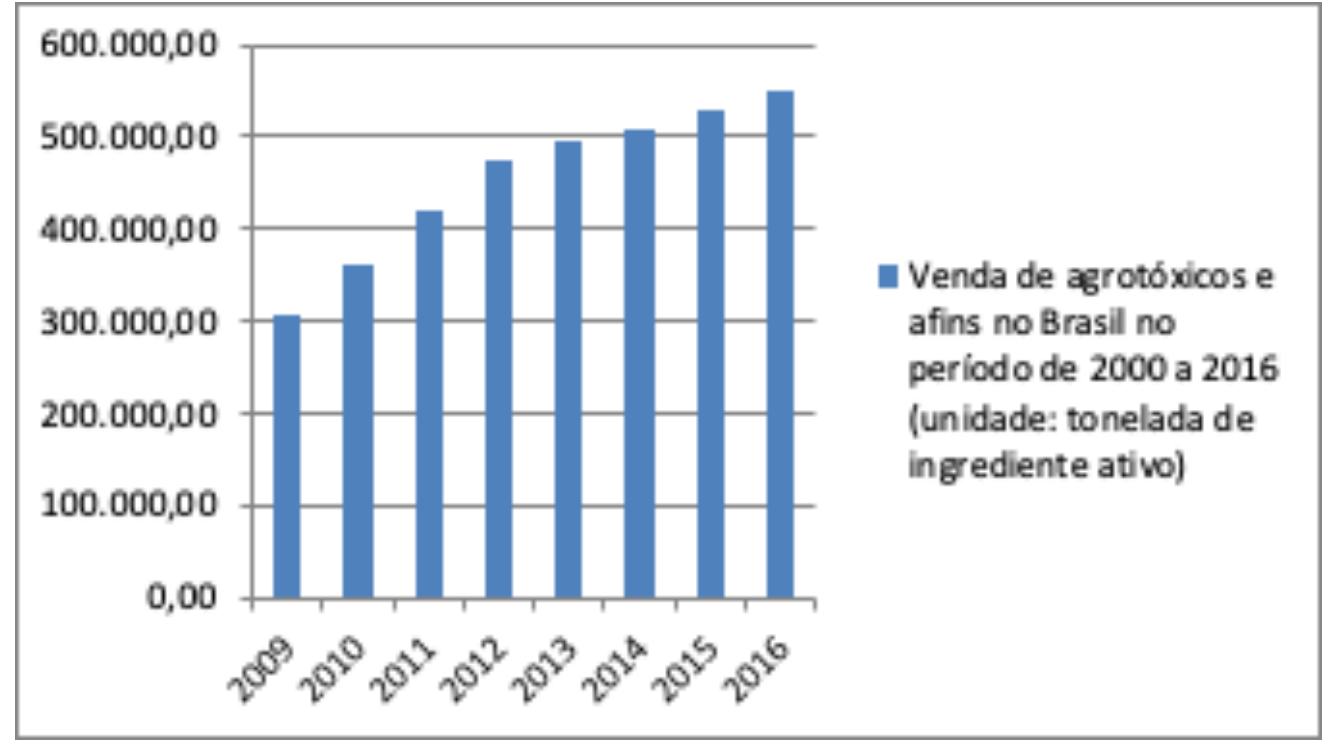

Fonte: IBAMA (s. d.).

Elaboração do gráfico: autor.

5 Destaca-se que o gráfico foi elaborado conforme a seção "Histórico de comercialização - "2000-2016" - "Histórico de comercialização de Químicos e Biológicos: 200o-2016", no sítio eletrônico do Instituto Brasileiro do Meio Ambiente e dos Recursos Naturais Renováveis, do qual não consta dados a respeito do ano de 2018 
O panorama maranhense em relação ao uso de agrotóxicos não se distancia muito da situação nacional. Observa-se, conforme gráfico abaixo, que existe diminuições na comercialização de agrotóxicos, mas desde o ano de 2008 até 2012 verifica-se um crescimento que corresponde ao momento de recrudescimento destacado no tópico anterior. Importa destaca que, conforme dados do Instituto Brasileiro do Meio Ambiente e dos Recursos Naturais Renováveis, o Maranhão figura como o segundo maior consumidor de agrotóxicos do nordeste, ficando atrás apenas da Bahia (IBAMA, s.d).

Gráfico 4 - Vendas de agrotóxicos e afins no Maranhão no período de 2000 a 2016 (unidade: tonelada de ingrediente ativo)

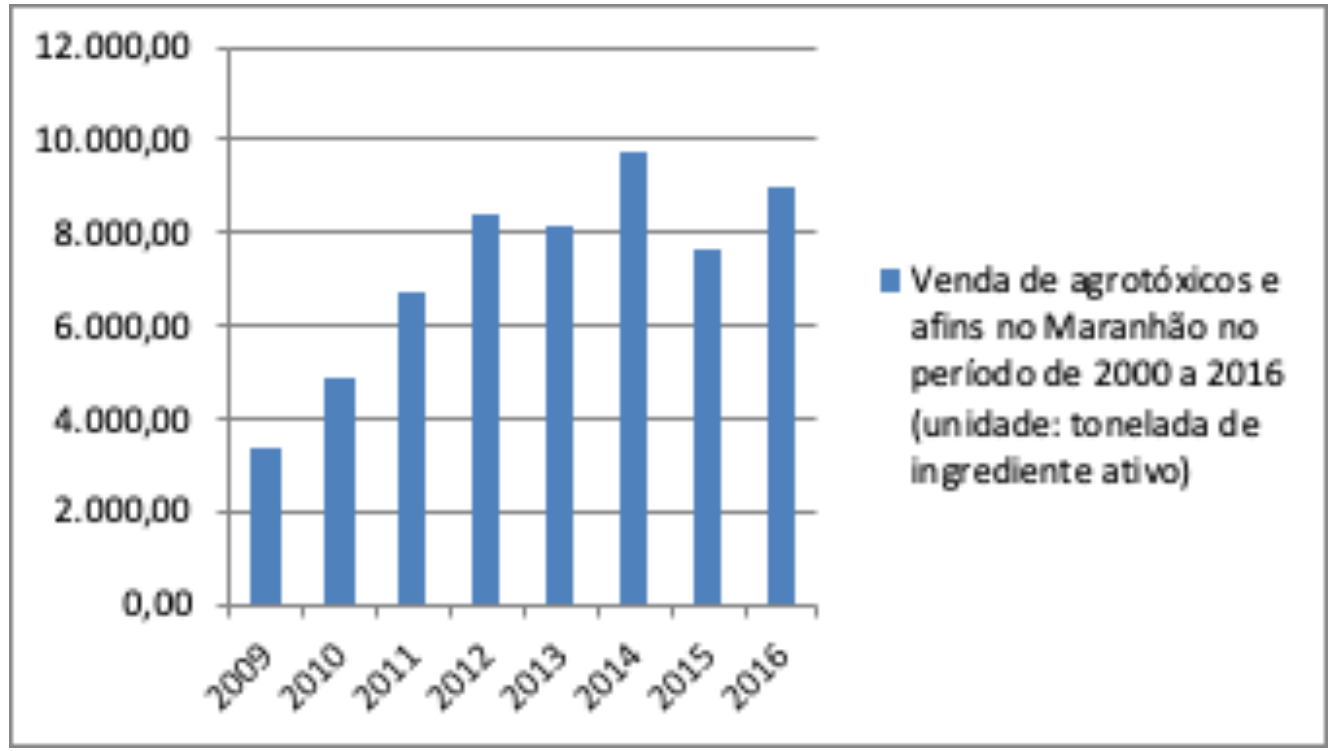

Fonte: IBAMA (s.d.).

Elaboração do gráfico: autor.

Entretanto, há neste contexto um enraizamento do conhecimento e do saber na biosfera e em formas de intervenções, como é o caso dos agroquímicos e outras tecnologias, contraposto aos saberes ambientais, estes enraizados por meio de novas práticas políticas, sociais e produtivas (LEFF, 2006, p.310). Leff(2006, p. 228-229) destaca que houve a apresentação de soluções tecnológicas para a escassez de recursos pelos países do Norte, implementandose processos mais eficazes que diminuíam o consumo e aumentavam a produtividade. Não obstante, além de dificuldades reais, isto possui limites. Neste sentido, para o referido autor, a produção da globalização econômica não compensa, pelos seus mecanismos, a destruição de ecossistemas, de práticas tradicionais, de risco e a insegurança econômica.

A respeito disto, destaca-se a existência de uma onda neocolonial:

[...] a mercantilização da natureza (a natureza como negócio), a artificialização da agricultura, a crescente presença de organismos geneticamente modificados (OGMs) e as decisões político-comerciais dos oligopólios que definem a matriz produtiva nacional na agricultura, além da redução do Estado e o estímulo a um suposto livre-cambismo, tornam o Brasil uma das principais economias do mundo, mas com pés de barro (AUGUSTO, et. al., 2008, p. 104). 
O derrame ambiental é observado em diversos conflitos socioambientais ${ }^{6}$, tais ocorre no Baixo Paranaíba maranhense, que será destacado no tópico seguinte, sendo situações que carregam também relações de poder e de saber. Sobre este aspecto, Shiva (2003, p. 22) destaca que os valores baseados do poder decorrem da ascensão do capitalismo comercial, no qual se introduz que o sistema dominante consiste em uma tradição universal, não uma tradição local globalizada.

Seguindo, também se observa o derrame de direito e extrações, que pode ser lido em conjunto com o derrame de compensação e justiça. Segundo Gudynas (2016, p. 37-38), o primeiro diz respeito às violações nos marcos dos direitos da pessoa, de direitos trabalhistas, do direito à informação e à participação e da Natureza. O segundo, por sua vez, referencia a ideia de compensação por danos sociais e ambientais de forma monetarizada, mercantilizando a natureza e a sociedade, escolhendo concepções de justiça essencialmente econômicas.

O agronegócio tem avançado no território nacional e maranhense, trazendo uma diversidade de externalidades à sociedade e ao meio ambiente, amparados por políticas estatais e pelo corpo jurídico-institucional existente ${ }^{7}$. Com isso, tal esquema econômico é consolidado com o apoio institucional e jurídico do Estado, bem como por correlações de forças políticas.

Neste aspecto, foi necessário, para a manutenção da modernização conservadora advinda da década de 1960, "um conjunto articulado de medidas governamentais e legislativas, em particular a instituição do crédito rural subsidiado pelos governos". Houve um reforço pós1990 do respaldo dos governos da ditadura civil-militar, com ampliação das políticas públicas compensatórias, apoio inconsistente do Estado e processo político-ideológico de cooptação popular (AUGUSTO, et. al., 2015, p. 102-103).

Ademais, destaca-se:

O modelo de desenvolvimento adotado, voltado para o crescimento econômico, estruturou-se por um aparato jurídico-institucional que possibilitou o incentivo às atividades econômicas, mas que afastou as necessidades e a realidade local, bem como as capacidades e particularidades ecológicas da região - projetando-se, desta forma, um desenvolvimento que não satisfaz liberdades e particularidades de ser e viver (BRUZACA, 2014, p. 52).

Faria (2002, p. 15) apresenta que na ordem sócio-econômica multifásica e policêntrica, o direito positivo enfrenta dificuldades na edição de normas vinculantes dos campos da vida sócio-econômica. Com isso, as regras que asseguravam a operacionalidade e a funcionalidade do sistema jurídico revelam-se ineficazes. Direitos individuais, coletivos e políticos são

\footnotetext{
6 No cenário brasileiro, pode-se destacar o caso de Lucas do Rio Verde/MT, que remete aos danos à saúde provocadas por intoxicação por agrotóxicos. Houve a ocorrência de leite materno contaminado pelos agrotóxicos, que também afetou a prole. Dentre eles destaca-se a presença de metabólico do diclorodifeniltricloroetano (DDT), proibido em 1998 no país, que acumula no corpo e pode causar diversas doenças, como o câncer. Com a produção da soja, recordista em produção, o uso de agrotóxicos aumentou e não se teve controle do raio de alcance dos herbicidas - inclusive afetando a produção de pequenos produtores (TENDLER, 2011). Outros casos além de Lucas do Rio Verde são destacados por Augusto et. al. (2015, passim), como o da Chapada do Apodi/CE, com a presença de transnacionais, havendo aplicação contínua de fungicidas e apropriação de terras; o do Pantanal Mato-grossense, com a contaminação das afluentes do Rio Paraguai e da planície pantaneira, acarretando em danos à saúde humana, à fauna e à flora; o do Polo Fruticultor de Exportação de Petrolina/PE, com ações governamentais para apoiar a "modernização da agricultura”, como a transposição do Rio São Francisco, que traz em contrapartida o incentivo ao agronegócio, o aumento da depência ao mercado externo e pioras nos índices sociais (analfabetismo, exploração sexual etc) e de saúde (aumento dos casos de danos aos trabalhadores e à população).

7 Neste sentido, em relação aos incentivos, Raquel Rigotto, professora da Universidade Federal do Ceará, destaca: “[...] os agrotóxicos têm estímulo fiscal para serem utilizados e consumidos no Brasil como um todo. Há um convenio que data de 1997, que oferece isenção fiscal de 6o\% do ICMS [Imposto sobre Operações relativas à Circulação de Mercadorias e Prestação de Serviços de Transporte Interestadual e Intermunicipal e de Comunicação], do COFINS [Contribuição para o Financiamento da Seguridade Social], do IPI [Imposto sobre Produtos Industrializados] e do PIS-PASEP [Programa de Integração Social - Programa de Formação do Patrimônio do Servidor Público] para todos os agrotóxicos vendidos nesse país. E no Ceará, e me parece que alguns outros Estados do Brasil, acharam isso pouco e estenderam a isenção a 100\%" (TENDLER, 2011).
} 
flexibilizados e desconstitucionalizados, e os conflitos coletivos cada vez menos se adéquam aos textos legais.

No mesmo sentido, Wolkmer (2006, p. 116-117) aponta que no cenário latino-americano, a ideologia neoliberal se comporta de maneira a eximir o Estado de sua responsabilidade, contribuindo para imensos desequilíbrios "ao ajustar e estabilizar a economia capitalista para as grandes burocracias e as elites financeiras internacionais". Com isso, as novas formas de dominação e exclusão afetaram as práticas políticas tradicionais e os padrões normativos reguladores da vida em sociedade.

Em termos específicos, no Brasil o novo desenvolvimentismo, com incentivos a atividades voltadas para a produção e exportação de bens primários, conforme a divisão internacional do trabalho, resulta em modificações do cenário jurídico nacional. Deste modo, pode-se observar interferências nas legislações, na formação jurídica, na atuação de instituições do sistema de justiça e na tutela de direitos.

Atualmente, a expansão do papel de instituições do sistema de justiça, como o do judiciário, e o primado do direito relacionam-se com o marco jurídico para o desenvolvimento, beneficiando o comercio, os investimentos e o lucro. Aqui, o Estado de direito e a reforma judicial traduzem-se em elementos para o desenvolvimento, sendo tarefa do judiciário clarificar e proteger direitos de propriedades, contratos, dentre outros (SOUSA, 2011, p. 31).

O modelo de desenvolvimento acaba legitimando-se política e economicamente, assumindo o direito papel importante neste cenário, Neste sentido, fazem os danos socioambientais serem considerados inevitáveis frente ao progresso, suscitando uma incompatibilidade de direitos. Argumenta-se que não é possível consagrar direitos associados ao desenvolvimento sem violar direitos sociais e culturais (SANTOS, 2013, p. 94).

Entretanto, existem resistências que buscam formas alternativas de produção àquela imposta pelo modelo neodesenvolvimentista. Ali se inserem comunidades tradicionais, como as compostas por camponeses e quilombolas, tais quais as que se observam no Baixo Parnaíba maranhense, que, resistindo às situações de violência e apropriação de seu território, articulam outras formas de ser, de viver e de fazer, alinhada às necessidades ambientais e sociais locais.

\section{IMPLICAÇÕES DAS RESISTÊNCIAS DE COMUNIDADES TRADICIONAIS FRENTE AO AGRONEGÓCIO NO BAIXO PARNAÍBA MARANHENSE}

Ao passo que se aprofunda a inserção do agronegócio no território maranhense, os conflitos fundiários, marcados por violências, são agudizados e a lógica de produção e apropriação degradante da natureza é consolidada. Assim, neste último momento, destaca-se avanço do agronegócio e as resistências na microrregião do Baixo Parnaíba maranhense $\mathrm{e}^{8-9}$, marcado por graves desrespeitos a direitos, pela violência no campo e pela degradação ambiental.

Pode-se observar o aprofundamento do agronegócio novamente com o plantio de soja. Para a elaboração do quadro seguinte foi utilizado também dados do Plano Agrícola 8 Conforme Gaspar e Andrade (2015, p. 111), tal microrregião é formada por 16 municípios, sendo eles: Água Doce do Maranhão, Anapurus, Araioses, Belágua, Brejo, Buriti, Chapadinha, Magalhães de Almeida, Mata Roma, Milagres do Maranhão, Santa Quitéria do Maranhão, Santana do Maranhão, São Benedito do Rio Preto, São Bernardo, Tutóia e Urbano Santos.

9 Tal microrregião foi objeto do documentário "A soja na terra das chapadas". Neste se destaca que a mesorregião do leste maranhense (na qual se insere a microrregião analisada) tem sido o palco da expansão do monocultivo, como ocorre com a soja. Vilson Ambrozi, então presidente da Associação dos Produtores Agrícolas do Cerrado do Leste Maranhense (APACL), destaca o seu deslocamento e de outros do sul do Brasil para a região, em 1990-1991, período de dificuldades econômicas do país. Em 1995/1998, mantiveram-se na localidade conforme atesta, tendo em vista a viabilidade na produção de soja. Em 1994 houve a inauguração do terminal de grãos da então Companhia Vale do Rio Doce, o que incentivou a produção de soja na mesorregião, considerando agora ponto estratégico para tal, estando o Baixo Parnaíba e o Alto Munim próximo do Porto do Itaqui e da Ponta da Madeira. O agronegócio avançou, ocupando áreas vistas como “inúteis" por órgãos que promovem o desenvolvimento agrícola (SANTOS, 20o8). 
Municipal, mas com referência à tabela 16 do Instituto Brasileiro de Geografia e Estatística ("Área plantada ou área destinada à colheita, área colhida, quantidade produzida, rendimento médio e valor da produção, unidades da federação e municípios, segundo principais produtos das lavouras temporárias e permanentes em ordem decrescente de área colhida").

Tabela 1 - Área plantada ou área destinada à colheita, área colhida, quantidade produzida, rendimento médio e valor da produção, unidades da federação e municípios, segundo principais produtos das lavouras temporárias e permanentes em ordem decrescente de área colhida.

\begin{tabular}{|c|c|c|c|c|c|c|c|c|c|}
\hline \multirow{2}{*}{ Município } & \multicolumn{9}{|c|}{ Ano } \\
\hline & 2008 & 2009 & 2010 & 2011 & 2012 & 2013 & 2014 & 2015 & 2016 \\
\hline $\begin{array}{l}\text { Água doce do } \\
\text { Maranhão }\end{array}$ & o & o & o & o & o & o & o & o & o \\
\hline Anapurus & $9 \cdot 790$ & $7 \cdot 737$ & 8.120 & 4.550 & 5.000 & 8.370 & 8.170 & 6.800 & 6.800 \\
\hline Araioses & o & o & o & o & o & o & o & o & o \\
\hline Belágua & o & o & o & o & o & o & o & o & o \\
\hline Brejo & 8.530 & 12.075 & 12.700 & $15 \cdot 380$ & 16.000 & 23.840 & 24.240 & 26.775 & $25 \cdot 500$ \\
\hline Buriti & 16.100 & 11.340 & 11.900 & 13.140 & 15.000 & 11.027 & 12.357 & 13.500 & 13.500 \\
\hline Chapadinha & 2.090 & 2.440 & 2.570 & 3.700 & 4.000 & 2.393 & 2.140 & 3.700 & 3.700 \\
\hline $\begin{array}{l}\text { Magalhães de } \\
\text { Almeida }\end{array}$ & 1.900 & 2.500 & 2.500 & 2.500 & 2.602 & 3.120 & 3.770 & $3 \cdot 325$ & 3.050 \\
\hline Mata Roma & 3.210 & $3 \cdot 500$ & 3.700 & $5 \cdot 350$ & 6.000 & 6.660 & 6.660 & 8.100 & 8.100 \\
\hline $\begin{array}{l}\text { Milagres do } \\
\text { Maranhão }\end{array}$ & 1.460 & 2.850 & 2.950 & 2.400 & 3.200 & 2.650 & 2.650 & 3.500 & $3 \cdot 500$ \\
\hline $\begin{array}{l}\text { Santa Quitéria do } \\
\text { Maranhão }\end{array}$ & 1.000 & 2.992 & 2.992 & $3 \cdot 550$ & 3.800 & 835 & 1.415 & 1.520 & 1.900 \\
\hline $\begin{array}{l}\text { Santana do } \\
\text { Maranhão }\end{array}$ & o & o & o & o & o & o & o & o & o \\
\hline $\begin{array}{l}\text { São Benedito do } \\
\text { Rio Preto }\end{array}$ & 190 & 270 & 440 & 500 & 600 & 610 & 650 & 1.240 & 1.240 \\
\hline São Bernardo & o & o & o & o & o & o & o & 1000 & 1310 \\
\hline Tutóia & o & o & o & o & o & o & o & o & o \\
\hline Urbano Santos & 400 & 200 & 450 & 500 & 600 & 1.590 & 1.690 & 1.350 & 1.350 \\
\hline Total & 44.670 & $45 \cdot 904$ & 48.322 & 51.570 & 56.802 & 61.095 & 63.742 & 70.810 & 69.950 \\
\hline
\end{tabular}

Fonte: IBGE (2008, 2009, 2010, 2011, 2012, 2013, 2014, 2015, 2016).

Elaboração do gráfico: autor. 
Conforme os dados apresentados, observa-se como na região paulatinamente a soja vem ganhando espaço, assim como ocorre no cenário nacional e estadual. Malgrado um declínio nos últimos dois anos abordados e as variações de quantidade e crescimento de ocupação de área para o monocultivo do grão, o plantio da soja também se consolida enquanto atividade econômica importante na microrregião.

Tal qual se observou em relação à ocupação do território, ao consumo de agrotóxicos, ao desrespeito a direitos no âmbito nacional e estadual, na microrregião agora analisada a situação de derrames e conflitos não é diferente. Isto é destacado no relatório do Grupo de Estudos Rurais e Urbanos (GERUR) intitulado "O agronegócio e os problemas socioambientais no Baixo Parnaíba Maranhense: a luta dos lavradores em defesa de um modo de vida”. Nele, descreve-se a presença dos chamados "gaúchos", com o monocultivo de soja, e de empresas como a Suzano/Paineiras, com o plantio de eucalipto ${ }^{10}$, que se valem do uso de agrotóxicos e técnicas prejudiciais ao meio ambiente. Este modo de produção afeta diretamente a população camponesa que desenvolve outras práticas de manejo em relação à natureza (GERUR, 2014, passim).

Shiraishi Neto (2011, p. 27) destaca que a ocupação de terras para monoculturas "se põe de forma antagônica ao vivenciado pelos diversos povos e comunidades tradicionais". Justamente, Almeida (2008, p. 133) apresenta que esses grupos são caracterizados por relações diferentes com a terra. As modalidades de uso comum da terra consistem em situações em que o uso dos recursos não se faz livre e individualmente por um determinado grupo, sendo instituídos por grupos familiares que compõem uma unidade social.

Trata-se de um conflito entre esquemas econômicos, modelos de produção e culturas no qual, por um lado, observa-se o monocultivo de soja, que se baseia no capital e num modelo de desenvolvimento dependente do mercado internacional; por outro, as práticas camponesas e de grupos étnicos, que são fundados em formas de ser, viver e criar próprios. Deste encontro, observam-se conflitos e resistências, como é possível observar em manifestações, em propostas legislativas, no ajuizamento de ações, dentre outras. Percebe-se, como apresenta Escobar (2007, p. 172-173), que no encontro com o desenvolvimento e a modernidade, as comunidades locais resistem ao aportarem seus recursos materiais e culturais ${ }^{11}$. Com isso, seus modelos econômicos híbridos e locais, refletem resistências culturais à transformação intentada pelo capital.

Quanto às resistências, pode-se destacar primeiramente propostas legislativas, visando modificar o quadro do avanço do agronegócio na microrregião. Neste sentido, em alguns de seus municípios, observam-se leis que proíbem a ampliação do monocultivo, do uso de sementes transgênicas, a obrigação de destinação de propriedade para plantio de mata nativa, como a Lei no 659 de 2008 do município de São Benedito do Rio Preto (SBRP, 2008). Entretanto, a mesma foi objeto de Ação Direta de Inconstitucionalidade, referente ao processo no ooo7737-50.2013.8.10.00oo, que tramitou no Tribunal de Justiça do Estado do Maranhão:

\footnotetext{
10 Conforme explicado anteriormente, enfatizou-se a soja em razão de ser o produto que mais ocupa área de plantio no Brasil, bem como pela relevância dada na economia do estado do Maranhão. Entretanto, existem outros monocultivos que também geram conflitos, como é o caso da cana-de-açúcar e do eucalipto. Sobre o eucalipto no Brasil, Shiva (2003, p. 73-74) destaca que seu plantio destrói florestas e comunidades. Há resistências da comunidade contra o "disseminar o verde” com eucaliptos, contrários à natureza e a seus ciclos. Ademais, "o eucalipto certamente aumentou o fluxo de dinheiro e mercadorias, mas resultou numa interrupção desastrosa dos fluxos de matéria orgânica e água no interior do ecossistema local”. Assim, o movimento "questiona a dominação da ciência florestal que reduziu todas as espécies a uma única (o eucalipto), todas as necessidades a uma única (a da indústria de polpa) e todo saber a um único (o do Banco Mundial e das autoridades florestais)”. Tal crítica também pode dialogar com os problemas de outros monocultivos, como o de soja.

11 As áreas nas quais a soja avança no Baixo Parnaíba maranhense eram habitadas há gerações por grupos camponeses, conforme atesta Marcelo Carneiro, professor da Universidade Federal do Maranhão, afirmando que os empreendimentos do agronegócio não encontraram as terras livres, aptas para expandir a fronteira agrícola. Atenta que não se trata de um deserto, havendo um confronto com um sistema de produção bastante antigo de agricultores, que são os agricultores familiares, que realizam atividade de produção extrativista vegetal e da criação de pequenos e grandes animais (SANTOS, 2008).
} 
AÇAO DIRETA DE INCONSTITUCIONALIDADE. LEI MUNICIPAL. VEDAÇÃO AO CULTIVO DE SEMENTES TRANSGÊNICAS. MATÉRIA DE RELEVÂNCIA NACIONAL. COMPETÊNCIA CONCORRENTE DA UNIÃO, ESTADOS E DISTRITO FEDERAL. AUSÊNCIA DE COMPETÊNCIA LEGISLATIVA MUNICIPAL. PROCEDÊNCIA DO PEDIDO. 1. Ação direta de inconstitucionalidade. Adequação da via processual eleita para impugnação de lei municipal. 2. Configura ofensa à Constituição Estadual dispositivo de lei municipal que traz vedação ao cultivo de sementes transgênicas, extrapolando os limites da competência legislativa municipal,conforme interpretação conjunta dos artigos 141 e 12, inciso II, alínea "f", da Constituição do Estado do Maranhão, e artigo 24, inciso VI, da Constituição Federal. 3. Arepartição de competências estabelecida na Constituição da República rege-se pela predominância de interesses de cada ente político. Assim, à União, cabe a edição de normas gerais, aos Estados, as normas suplementares e, aos Municípios, as normas atinentes às peculiaridades do interesse local. 4. Ação Direta de Inconstitucionalidade julgada procedente para declarar inconstitucional, com efeitos ex nunc, o art. $1^{\circ}$, parágrafo único, da Lei municipal $n^{\circ}$. 659/2008, de São Benedito do Rio Preto (MARANHÃO, 2014, destaques nossos).

Com isso, foi julgado parcialmente inconstitucional quanto ao previsto no artigo $1^{\mathbf{0}}$, parágrafo único: "Fica proibida a ampliação onde já estiverem implantados e a implantação de novos empreendimentos de monocultura de eucalipto, soja, cana de açúcar e outros" (SBRP, 20o8). Não obstante o resultado da referida ação, observa-se como a mobilização da comunidade suscitou mudanças legislativas e uma consequente atuação do judiciário.

Consoante apresenta Santos (2013, p. 95), somente é possível o questionamento do esquema econômico, tal qual o adotado no Brasil e consequentemente no Maranhão, pelo questionamento por meio de movimentos e organizações sociais. Para o autor, estes expõem "o lado destrutivo deste modelo sistematicamente ocultado, dramatizar[am] a sua negatividade e forç [am] a entrada desta denúncia na agenda política”.

Seguindo, situação que se relaciona com o derrame territorial diz respeito ao cenário de conflitos fundiários. Isto repercute na atuação administrativa de órgãos como o Instituto Nacional de Colonização e Reforma Agrária (INCRA), bem como do Instituto de Terras do Maranhão (ITERMA). Ademais, o judiciário e outras instituições do sistema de justiça envolvem-se, principalmente no que diz respeito ao ajuizamento de ações possessórias.

A atuação administrativa, com órgãos fundiárias, não se distancia do apresentado por Santos (2013, p. 99), para quem o agronegócio repercute na "grilagem de terras dos povos tradicionais e das áreas da reforma agrária”. Isto pode ser observado, por exemplo, na lentidão e baixos números quanto à titulação de terras na microrregião do Baixo Parnaíba maranhense. Carneiro (2008, p. 96-97) destaca que a atuação do INCRA e do ITERMA é tímido na microrregião homogênea de Chapadinha (Buriti, Brejo, Anapurus e Chapadinha), que faz parte do Baixo Parnaíba maranhense. Atenta ao pequeno número de terras tituladas, às poucas famílias beneficiárias e às diminutas áreas desapropriadas para fins de reforma agrária. Em dado específico, na região destaca a inexistência de titulação de comunidades remanescentes de quilombo.

Quanto às comunidades quilombolas, conforme Comissão Pró-Índio de São Paulo, com dados até o ano de 2014, inexiste titulação de comunidades quilombolas em todo Baixo Parnaíba maranhense (CPISP, s.d.). Tais instabilidades quanto à garantia da terra e do território resultam na agudização dos conflitos possessórios, cujas resistências das comunidades encontram como palco o judiciário e outras instituições do sistema de justiça.

No que diz respeito aos conflitos possessórios, conforme expõe Santos (2011, p. 101), no âmbito da revolução democrática da justiça é necessário um outro relacionamento com os movimentos sociais. Suas queixas refletem a insensibilidade quanto a seus problemas e direitos. Atenta-se à acusação por tais movimentos de uma parcialidade do judiciário, 
observada quando da concessão de liminares de reintegração de posse aos proprietários rurais. Não obstante, existem decisões que requerem justificação de posse e, por algumas vezes, nega-se o pedido de liminar por descumprimento da função social da propriedade.

Como visto, o agronegócio é marcado por ser ambiental, social e culturalmente prejudicial para as comunidades locais. Não obstante, encontram tutela jurídica por meio de instrumentos processuais, como é o caso das ações possessórias. Bruzaca e Vieira (2017, p. 195-196) destacam o cenário de conflitos possessórios na região, dando ênfase à situação do município de Brejo, no qual se encontram comunidades quilombolas como Depósito, Saco das Almas e São Bento. Detalham o processo que envolve esta última, apresentando-se as dissonâncias existentes no uso da via processual possessória para compreender a particular relação que as comunidades quilombolas possuem com a terra.

O uso da propriedade, como atenta Costa Neto (2003, p. 53), deve estar atrelado a uma finalidade de cunho social. Esta função social se materializa quando proporcionada uma existência digna. Significa, em outras palavras, atrelar o exercício da propriedade a outros valores, alheios ao proprietário, como: construção de uma sociedade livre, justa e solidária, erradicação da pobreza e diminuição das desigualdades. Entretanto, o que se observa é a existência de instrumentos do processo civil que asseguram a continuidade do exercício do domínio sobre a propriedade, mesmo que não cumpram com a sua função social - e ambiental.

Nas situações de conflitos possessórios envolvendo o agronegócio, como os acima mencionados, aspectos como a relação com o ambiente empreendida pelas comunidades ou até mesmo a função socioambiental da propriedade não são considerados. Neste sentido, segue uma concepção estritamente civilista, distanciando-se de uma leitura constitucional e ambiental nos conflitos envolvendo o agronegócio. A este respeito, Wolkmer (2001, p. 107) apresenta que os conflitos internalizados por sujeitos sociais são analisados tendo em vista a legislação convencional, cuja decisão se dá de forma inadequada, gerando um agravamento maior do conflito.

Por outro lado, são os novos agentes que se marcam pela potencialidade na produção jurídica, com a captação do fenômeno jurídico por meio da informalidade das ações de atores coletivos, consensualizados pelo interesse do todo comunitário, independente dos rituais formais e institucionais (WOLKMER, 2001, p. 119). Como destacado, as comunidades inseridas no contexto de conflitos provocados pelo monocultivo promovem resistências por meio de mudanças legislativas, de pressões sobre os órgãos fundiários ou de resistências ao direito aplicado pelo judiciário.

Com isso, entende-se que as resistências das comunidades tradicionais associam-se com uma luta de pela soberania cultural e epistemológica que, para Marchi (2016, p. 5354) referencia uma re-apropriação de sentidos e símbolos, bem como uma re-apropriação da terra e dos recursos em conformidade com a cosmovisão e o estilo de vida das comunidades, tratando-se de uma contra-força à narrativa dominante.

O agronegócio tem avançado agressivamente no território nacional e maranhense, trazendo uma diversidade de externalidades à sociedade e ao meio ambiente, amparados por políticas estatais e pelo corpo jurídico-institucional existente. Entretanto, existem resistências, como destacado, que buscam formas alternativas de produção àquela imposta pelo modelo de desenvolvimento adotado. Ali se inserem grupos formados por camponeses e quilombolas, por exemplo, que resistindo às situações de violência e apropriação de seu território articulam outras formas de ser, de viver e de fazer, alinhada às necessidades ambientais e sociais locais. 


\section{CONSIDERAÇÕES FINAIS}

O presente artigo trouxe um panorama a respeito do avanço do agronegócio no território brasileiro e seus consequentes impactos, como os provocados ao ambiente pelo uso de técnicas, a exemplo dos agrotóxicos, e as implicações sobre os direitos. Especificamente, em relação ao Maranhão e ao Baixo Parnaíba Maranhense, pode-se observar que se mantém a política neodesenvolvimentista nacional e, consequentemente, um cenário social e ambiental marcado por conflitos, como os envolvendo comunidades tradicionais.

Consolida-se o modelo de desenvolvimento que, assentado na divisão internacional do trabalho, impõe ao Brasil a condição de produtor de bens primários para exportação, guardando relações com aquele existente na década de 1960 . Sob o nome de neodesenvolvimentismo ou novo desenvolvimentismo, tem no agronegócio uma das principais atividades, sustentada pela atuação do Estado.

Com isso, observa-se o aprofundamento das monoculturas no espaço maranhense, assim como no Baixo Parnaíba maranhense, também com cumplicidades estatais, sejam elas administrativas ou jurídicas. Considerada atividade importante para a economia nacional, estadual e microrregional, justificam-se os impactos causados pelo agronegócio ao ambiente, à sociedade e aos direitos.

Não obstante, frente a tais avanços percebem-se resistências, guiadas por outra forma de ser, viver e criar, como a de comunidades tradicionais, a exemplo de camponeses e quilombolas. No Baixo Parnaíba maranhense isto é possível de se observar com as reivindicações das comunidades de São Benedito do Rio Preto e nas resistências das comunidades quilombolas de Brejo.

Deste modo, a atuação das comunidades tradicionais repercute na contraposição ao dominante esquema de desenvolvimento existente na localidade, que refletem outras formas de organização econômica, de relação com a terra e com o ambiente. Disto, possibilita-se questionar a primazia daquele modelo na sociedade e no espaço jurídico, buscando caminhos para a efetivação de direitos.

\section{REFERÊNCIAS}

ALMEIDA, Alfredo Wagner Berno de. Apresentação. In: SHIRAISHI NETO, Joaquim. Direito dos Povos e das Comunidades Tradicionais no Brasil: Declarações, Convenções Internacionais e Dispositivos Jurídicos definidores de uma Política Nacional. Manaus: UEA, 2007. p. 8-16.

Terra de quilombo, terras indígenas, "babaçuais livre", "castanhais do povo", faixinais e fundos de pastos: terras tradicionalmente ocupadas. 2. ed. Manaus: PGSCA-UFMA, 2008.

AUGUSTO, Lia Giraldo da Silva, et. al. Parte 2 - Saúde, ambiente e sustentabilidade. In.: CARNEIRO, Fernando Ferreira, et. al. (Orgs.). Dossiê ABRASCO: um alerta sobre os impactos dos agrotóxicos na saúde. São Paulo: Expressão Popular, 2015. pp. 89-191.

BIELSCHOWSKY, Ricardo. Ideologia e desenvolvimento: Brasil, 1930-1964. In.: PÁDUA, José Augusto (Org.). Desenvolvimento, justiça e meio ambiente. Belo Horizonte: Editora UFMG, 2009. p. 22-63. 
BRUZACA, Ruan Didier. A tutela do modo de vida tradicional de remanescentes de quilombos e a atuação do judiciário no contexto maranhense da duplicação da estrada de Ferro Carajás. 2014. 13of. Dissertação - Mestrado em Instituições do Sistema de Justiça, Universidade Federal do Maranhão, São Luís, 2014.

VIEIRA, Adriana Dias. Linguagem dos juristas frente a representações jurídicoculturais de povos e comunidades tradicionais: o caso do conflito possessório envolvendo a comunidade quilombola de São Bento, Brejo/MA. In: Prisma Jurídico, v.16, n.1, p.181-204, 2017.

CARNEIRO, Marcelo Domingos Sampaio (Coord). In: A expansão e os impactos da soja no Maranhão. In: A agricultura familiar da soja na região sul e o monocultivo no Maranhão. Rio de Janeiro: FASE, 2008, p. 75-146.

COSTA NETO, Nicolau Dino de Castro e. Proteção jurídica do meio ambiente: florestas. Belo Horizonte: Del Rey, 2003.

CPISP. Terras de quilombos com processos no INCRA por estado. São Paulo, s.d. Disponível em: <http://www.cpisp.org.br/terras/Mapa/mapa.aspx?VerTerras=r>. Acesso em 20 fev. 2018.

ESCOBAR, Arturo. Displacement, Development, and Modernity in the Colombian Pacific. In: International Social Science Journal, vol. 55, n. 175, 2003, pp. 157-168.

La Invencíon del Tercer Mundo. Caracas: Edición Fundación Editorial el perro y la rana, 2007 .

GASPAR, Rafael Bezerra. ANDRADE, Maristela de Paula. Gaúchos no Maranhão: agentes, posições sociais e trajetórias em novas fronteiras do agronegócio. In: Revista Pós Ciências Sociais. v.11, n.22, p. 109-128, jul/dez. 2014.

GERUR. O agronegócio e os problemas socioambientais no Baixo Parnaíba Maranhense: a luta dos lavradores em defesa de um modo de vida. São Luís, 2014.

GUDYNAS, Eduardo. Extractivismos em América del Sur: conceptos y sus efectos derrame. In.: ZHOURI, Andréa. BOLADOS, Paola, CASTRO, Edna (Orgs.). Mineração na América do Sul: neoextrativismo e lutas territoriais. São Paulo: Annablume, 2016, pp. 23-44.

IBAMA. Vendas de agrotóxicos e afins no Brasil no período de 2000 a 2016 (unidade: tonelada de ingrediente ativo). Brasília, s.d. Disponível em: <http://ibama.gov.br/ phocadownload/qualidadeambiental/relatorios/2016/Historico_200o_2016.xls>. Acesso em 20 fev. 2018.

IBGE. Plano Agrícola Municipal. Brasília, 20o8. Disponível em: <http://www.ibge.gov.br/ home/estatistica/economia/pam/2008/>. Acesso em 20 fev. 2018.

Plano Agrícola Municipal. Brasília, 2009. Disponível em: <http://www.ibge.gov.br/ home/estatistica/economia/pam/2009/>. Acesso em 20 fev. 2018. 
Plano Agrícola Municipal. Brasília, 2010. Disponível em: <http://www.ibge.gov.br/ home/estatistica/economia/pam/2010/>. Acesso em 20 fev. 2018.

Plano Agrícola Municipal. Brasília, 2011. Disponível em: <http://www.ibge.gov.br/ home/estatistica/economia/pam/2011/>. Acesso em 20 fev. 2018.

Plano Agrícola Municipal. Brasília, 2012. Disponível em: <http://www.ibge.gov.br/ home/estatistica/economia/pam/2012/>. Acesso em 20 fev. 2018.

Plano Agrícola Municipal. Brasília, 2013. Disponível em: <http://www.ibge.gov.br/ home/estatistica/economia/pam/2013/>. Acesso em 20 fev. 2018.

Plano Agrícola Municipal. Brasília, 2014. Disponível em: <http://www.ibge.gov.br/ home/estatistica/economia/pam/2014/>. Acesso em 20 fev. 2018.

Plano Agrícola Municipal. Brasília, 2015. Disponível em: <http://www.ibge.gov.br/ home/estatistica/economia/pam/2015/>. Acesso em 20 fev. 2018.

Plano Agrícola Municipal. Brasília, 2016. Disponível em: <http://www.ibge.gov.br/ home/estatistica/economia/pam/2016/>. Acesso em 20 fev. 2018.

LEFF, Enrique. Racionalidade ambiental: a reapropriação social da natureza. Rio de Janeiro: Civilização Brasileira, 2006.

MARCHI, Elisa. Accommodation of Cultural Diversity and Collective Rights at the Crossroads of Conservation Discourses: the Case of Indigenou Communities in Oaxaca, Mexico. Tese (Tese de Doutorado em Ciências Jurídicas). UNIFI. Florença, p. 270. 2016.

MOTA, Carlos Guilherme. Para uma visão de conjunto: a história do Brasil pós-193o e seus juristas. In: MOTA, Carlos Guilherme. SALINAS, Natasha. Schimitt Caccia (coords.). Os juristas na formação do Estado-Nação brasileiro: 1930-dias atuais. São Paulo: Saraiva [Kindle Version], 2010.

SANTOS, Boaventura de Sousa. Para uma revolução democrática da justiça. 3. ed . São Paulo: Cortez, 2011.

Direitos humanos, democracia e desenvolvimento. In: SANTOS, Boaventura de Sous, CHAUÍ, Marilena. Direitos humanos, democracia e desenvolvimento. São Paulo: Cortez, 2013, p. 41-133.

SANTOS, Murilo (diretor). A soja na terra das chapadas [documentário]. São Luís: FASE, SMDH, 2008.

SBRP (São Benedito do Rio Preto). Lei no 659 de 2oo8. São Benedito do Rio Preto, 2008.

SCHLESINGER, Sérgio. NUNES, Sidemar Presotto. A soja na agricultura familiar: os casos de Planalto (PR) e Três de Maio (RS). In: A agricultura familiar da soja na região sul e o monocultivo no Maranhão. Rio de Janeiro: FASE, 2008, p. 75-146. 
SHIRAISHI NETO, Joaquim. Disputa pela redefinição da região amazônica. In.: SHIRAISHI NETO, Joaquim, et al. Meio ambiente, território e práticas jurídicas: enredos em conflito. São Luís: EDUFMA, 2011. p. 23-52.

SHIVA, Vandana. Monoculturas da mente: perspectivas da biodiversidade e da biotecnologia. São Paulo: Gaia, 2003.

TENDLER, Sílvio (diretor). O veneno está na mesa [documentário]. Rio de Janeiro: Caliban Produções Cinematográficas, 2011. Disponível em: <https://www.youtube.com/ watch?v=V9KJyRghxJI>. Acesso em 26 fev. 2017.

MARANHÃO. Tribunal de Justiça do Estado do Maranhão. Processo no ooo773750.2013.8.10.000o. São Luís, 2014 .

WOLF, Eric R. Sociedades camponesas. Rio de Janeiro: Zahar Editores, 1976.

WOLKMER, Antonio Carlos. Pluralismo jurídico: fundamentos de uma nova cultura no Direito. 3 ed. rev. e atual. São Paulo: Editora Alfa Omega, 2001.

Pluralismo jurídico, direitos humanos e interculturalidade. In: Revista Seqüência, $n$ 53, dez. 2006, p. 113-128. 